Article

\title{
Phytochemical and Biological Studies of Agave attenuata
}

\section{Komal Rizwan ${ }^{1}$, Muhammad Zubair ${ }^{1}$, Nasir Rasool ${ }^{1}$, Muhammad Riaz ${ }^{1}$, Muhammad Zia-Ul-Haq ${ }^{2}$ and Vincenzo de Feo ${ }^{3, *}$}

1 Department of Chemistry, Government College University, Faisalabad 38000, Pakistan;

E-Mails: komal.rizwan45@yahoo.com (K.R.); zubairmkn@yahoo.com (M.Z.); nasirhej@yahoo.co.uk (N.R.); riaz_453@yahoo.com (M.R.)

2 Research Institute of Pharmaceutical Sciences, Department of Pharmacognosy, University of Karachi, Karachi 75270, Pakistan; E-Mail: ahirzia@ gmail.com

3 Department of Pharmaceutical and Biomedical Sciences, University of Salerno, Via Ponte don Melillo, I-84084 Fisciano (Salerno), Italy

* Author to whom correspondence should be addressed: E-Mail: defeo@unisa.it; Tel.: +39-089-959751; Fax: +39-089-969602.

Received: 27 March 2012; in revised form: 14 April 2012 / Accepted: 4 May 2012 /

Published: 24 May 2012

\begin{abstract}
The present study was conducted to examine various biological activities of a methanol extract of Agave attenuata leaves. GC-MS analysis of the $n$-hexane fraction from the extract revealed the presence of 31 compounds, with mono-2-ethylhexyl phthalate (11.37\%), 1,2-benzenedicarboxylic acid (6.33\%), $n$-docosane $(6.30 \%)$ and eicosane $(6.02 \%)$ as the major components. The leaves contained appreciable levels of total phenolic contents (10.541-39.35 GAE, mg/100 g) and total flavonoid contents (43.35-304.8 CE, mg/100 g). The extract and some of its fractions showed moderate antimicrobial effects. Leaves extract and fractions also exhibited a good antioxidant potential when measured by DPPH radical scavenging activity and inhibition of lipid peroxidation assays. The hemolytic effect of the plant was found to be in a range of $1.01 \%-2.64 \%$. From the present study it is concluded that this plant could be used as a source of natural antioxidants and functional food nutraceutical applications.
\end{abstract}

Keywords: Agave attenuata; GC-MS; peroxidation; volatile fraction; flavonoids; phenolics 


\section{Introduction}

Plants possess an almost limitless ability to biosynthesize phytochemicals, which serve as a source for natural antioxidants and as plant defense mechanisms against predation by microorganisms, herbivores and insects [1,2]. Gupta [3] asserted that in comparison to synthetic drugs, antimicrobials and antioxidants of plant origin are not associated with many side effects and has an enormous therapeutic potential to heal many infections and diseases.

Many species of the genus Agave constitute an important source of steroidal sapogenins, mainly hecogenin [4]. In the pharmaceutical industry, these natural compounds are used for the semisynthesis of medicinal steroids, as corticosteroids, sexual hormones and steroid diuretics [5]. The most investigated species of the genus is A. americana $\mathrm{L}$. that has been reported for its antibacterial and anti-inflammatory properties [6]. Some other species possess anticancer properties [7]. Antimicotic, antiviral and antituberculosis properties have also been ascribed to this genus. The antimicrobial activity of some species against pathogens has been previously reported [8,9]. Some species of this genus are used in Chinese Traditional Medicine in treatment of scabies, tumors, dysentery, and as insecticides [10-12].

Agave attenuata Salm-Dyck is native to central Mexico and tropical America. The plant is commonly grown as a garden plant. In fact, the plant has no teeth or terminal spines; this property makes it an ideal plant for areas adjacent to footpaths. It is a hardy survivor of drought, tolerating heat well and moderate salt exposure. Previous literature reports showed the presence in the plant of steroidal saponins [13-15]. The plant may provide a substitute for niclosamide and be used safely for snail control by rural communities [16] and has been proposed as a contact poison for Bulinus africanus [17].

Despite its multipurpose uses, very little data exists on its chemical constituents; therefore the current study reports the chemical composition of $n$-hexane fraction of $A$. attenuta leaves and the in vitro antimicrobial, antioxidant, hemolytic activities of the methanol extract and fractions thereof. This study will provide base-line data for further detailed investigations of various biological activities of this plant and of its use as a functional food.

\section{Results and Discussion}

\subsection{GC-MS Analysis of n-Hexane Fraction}

The GC-MS analysis of $n$-hexane fraction from methanol extract enabled the identification of 31 components, representing $90.32 \%$ of the total fraction. This volatile fraction consisted of a mixture of different classes of compounds. The major constituents were found to be mono-2-ethylhexyl phthalate (11.37\%), 1,2-benzene dicarboxylic acid (6.33\%), $n$-docosane (6.30\%), and eicosane (6.02\%) (Table 1). Gutierrez et al. [18] reported the chemical composition of a lipophilic extract of Agave sisalana fiber. Most of $n$-alkanes and fatty acids identified in $A$. sisalana fiber were also identified in volatile fraction of $A$. attenuata leaves. 
Table 1. Chemical constituents of $A$. attenuata leaves $n$-hexane fraction.

\begin{tabular}{|c|c|c|}
\hline Retention Time & Compounds & Area \% \\
\hline 3.338 & Benzothiazole & 0.94 \\
\hline 4.186 & Tetradecane & 0.79 \\
\hline 4.686 & $n$-Undecane & 2.12 \\
\hline 5.005 & $n$-Pentadecane & 2.91 \\
\hline 5.711 & (E)-1-Methoxymethoxy-1-tetradecane-3-ol & 0.88 \\
\hline 5.915 & $n$-Hexadecane & 2.28 \\
\hline 6.029 & 1,2-Benzenedicarboxylic acid & 6.33 \\
\hline 6.877 & $n$-Heptadecane & 2.60 \\
\hline 7.856 & $n$-Octadecane & 2.51 \\
\hline 7.958 & Phytane & 1.29 \\
\hline 8.339 & 2-Undecanone & 0.57 \\
\hline 8.823 & Nonadecane & 2.42 \\
\hline 9.090 & Hexadecanoic acid & 3.68 \\
\hline 9.437 & Palmitic acid & 4.57 \\
\hline 9.773 & Icosane & 2.43 \\
\hline 10.695 & Heneicosane & 3.44 \\
\hline 10.752 & 9-Octadecanoic acid & 3.65 \\
\hline 10.951 & Octadecanoic acid & 0.60 \\
\hline 11.099 & Linoleic acid & 2.57 \\
\hline 11.577 & $n$-Docosane & 6.30 \\
\hline 12.430 & Eicosane & 6.02 \\
\hline 13.255 & Tetracosane & 2.01 \\
\hline 14.052 & Pentacosane & 4.30 \\
\hline 14.541 & Mono-2-ethylhexyl phthalate & 11.37 \\
\hline 14.820 & $n$-Hexacosane & 3.98 \\
\hline 15.657 & $n$-Octacosane & 0.60 \\
\hline 15.861 & Tetracosanoic acid & 0.76 \\
\hline 17.398 & Nonacosane & 3.57 \\
\hline 18.536 & $n$-Triacontane & 2.15 \\
\hline 19.366 & 2,5-Cyclohexadiene-1,4-dione & 0.85 \\
\hline 19.879 & Nonadecane & 1.83 \\
\hline Total & & $90.32 \%$ \\
\hline
\end{tabular}

\subsection{Antioxidant Potential of A. attenuata Leaves}

The amounts of Total Phenol Content (TPC) and Total Flavonoid Content (TFC) extracted with different solvents from leaves of A. attenuata are reported in Table 2. These values ranged from 10.54 to 39.35 gallic acid equivalents (GAE) $(\mathrm{mg} / 100 \mathrm{~g}$ of dry plant matter) and from 304.8 to 43.35 catechin equivalents (CE) (mg/100g of dry plant matter), respectively. The ability of different solvents to extract TPC was found as follows: methanol $(39.35 \%)>$ chloroform $(19.3 \%)>$ ethylacetate $(14.5 \%)>n$-butanol $(10.65 \%)>n$-hexane $(10.54 \%)$. 
Table 2. Antioxidant potential of the methanol extract and its fractions from A. attenuata leaves.

\begin{tabular}{|c|c|c|c|c|c|}
\hline $\begin{array}{l}\text { Extract or } \\
\text { Reference } \\
\text { Compound } \\
\end{array}$ & $\begin{array}{c}\text { Total Phenolic } \\
\text { Contents (GAE } \\
\text { mg/100 g) } \\
\end{array}$ & $\begin{array}{c}\text { Total Flavonoid } \\
\text { Contents (CE } \\
\text { mg/100 g) } \\
\end{array}$ & $\begin{array}{c}\text { DPPH } \\
\text { (\% inhibition, } \\
\text { 0.1 } \mathrm{mg} / \mathrm{mL} \text { ) }\end{array}$ & $\begin{array}{c}\text { Inhibition in } \\
\text { Linoleic Acid } \\
\text { System (\%) }\end{array}$ & $\begin{array}{c}\text { Reducing Power } \\
\text { (Absorbance, nm } \\
1 \mathrm{mg} / \mathrm{mL} \text { ) } \\
\end{array}$ \\
\hline Methanol & $39.35 \pm 0.69^{a}$ & $304.8 \pm 5.02^{\mathrm{a}}$ & $73.97 \pm 1.49^{b}$ & $70.35 \pm 1.34^{b}$ & $0.631 \pm 0.016^{b}$ \\
\hline Chloroform & $19.3 \pm 0.91^{b}$ & $79.8 \pm 3.91^{\mathrm{c}}$ & $64.94 \pm 0.85^{c}$ & $60.25 \pm 1.02^{\mathrm{d}}$ & $0.664 \pm 0.012^{b}$ \\
\hline Ethylacetate & $14.56 \pm 1.11^{\mathrm{c}}$ & $197.2 \pm 4.96^{\mathrm{b}}$ & $73.36 \pm 0.94^{b}$ & $67.78 \pm 1.64^{b, c}$ & $0.487 \pm 0.015^{b}$ \\
\hline$n$-Butanol & $10.65 \pm 1.24^{\mathrm{d}}$ & $71.5 \pm 2.96^{\mathrm{c}}$ & $65.21 \pm 0.98^{c}$ & $66.23 \pm 1.82^{c}$ & $0.625 \pm 0.019^{b}$ \\
\hline$n$-Hexane & $10.54 \pm 0.40^{\mathrm{d}}$ & $43.35 \pm 2.99^{\mathrm{d}}$ & $61.41 \pm 1.07^{\mathrm{d}}$ & $50.12 \pm 1.12^{\mathrm{e}}$ & $0.219 \pm 0.013^{c}$ \\
\hline Ascorbic Acid & - & - & - & - & $0.8 \pm 0.021^{\mathrm{a}}$ \\
\hline BHT & - & - & $90.3 \pm 2.04^{\mathrm{a}}$ & $84.3 \pm 2.33^{\mathrm{a}}$ & - \\
\hline
\end{tabular}

Data are expressed as the mean \pm standard deviation; values having different letters differ significantly $(p<0.05)$.

The ability of solvents on TFC values was found in the following order: $100 \%$ methanol (304.8\%) > ethylacetate $(197.2 \%)>$ chloroform $(79.8 \%)>n$-butanol $(71.5 \%)>n$-hexane $(43.35 \%)$. The DPPH radical scavenging activity of extract and fractions $(0.1 \mathrm{mg} / \mathrm{mL})$ ranged from 61.41 to $73.97 \%$. Methanol extract showed the highest scavenging activity $(73.97 \%)$, followed by ethyl acetate (73.36\%), $n$-butanol $(65.21 \%)$, chloroform $(64.94 \%)$ and $n$-hexane $(61.41 \%)$ fractions, respectively. The percent inhibition of linolei c acid oxidation ranged from $50.12 \%$ to $70.35 \%$, whereas BHT provided inhibition at the level of $84.7 \%$. The methanol extract exhibited the highest inhibition of linoleic acid oxidation (70.35\%) followed by ethylacetate $(67.78 \%), n$-butanol $(66.23 \%)$, chloroform $(60.25 \%)$ and $n$-hexane $(50.12 \%)$ fractions, respectively. When the results of DPPH scavenging activity and the percent inhibition of linoleic acid oxidation were compared with standard BHT, all the samples showed significantly $(p<0.05)$ minor activity. The reducing potential of the tested extract and fractions was observed at concentrations of $1 \mathrm{mg} / \mathrm{mL}$. The absorbance recorded for the tested samples in this assay resulted in the range of $0.219-0.664 \mathrm{~nm}$ [19]. The maximum absorbance $(0.664 \mathrm{~nm})$ was recorded for chloroform fraction, while the minimum was for $n$-hexane $(0.20 \mathrm{~nm})$ one. The reducing power of different extracts and fractions decreased in the following order: chloroform $>100 \%$ methanol $>n$ butanol $>$ ethylacetate $>n$-hexane. When these results were compared with standard ascorbic acid $(0.8$ $\mathrm{nm}$ ), all the samples showed a minor reducing power (Table 2). Results indicated that among all the extract and fractions; the methanolic extract of plant leaves exhibited the highest amount of TPC and TFC, and correspondingly the highest antioxidant activity as measured by DPPH radical scavenging and inhibition of linoleic acid oxidation; whereas, $n$-hexane fraction demonstrated the least antioxidant activity probably because of its low polarity [20].

\subsection{In Vitro Hemolytic Activity}

Hemolytic activity was studied because, even if the plant possesses potent antioxidant and antimicrobial activities, its use in medicine will be impossible in the presence of these hemolytic effects linked to the presence of saponins. The total hemolysis (100\%) was obtained using $20 \mu \mathrm{L}$ of Triton X-100 (0.1\%). Chloroform fraction showed the highest hemolytic effect $(2.64 \%)$ [21], followed by $n$-hexane $(2.09 \%)$, methanol extract $(1.46 \%)$, ethylacetate $(1.40 \%)$ and $n$-butanol $(1.01 \%)$ fractions. 
The hemolytic effect of $n$-butanol fraction was less than other fractions (Table 3 ). However, data obtained are in a safe range and the plant extracts may be safe for human use.

Table 3. Hemolytic activity, as a percentage of hemolysis caused by A. attenuate leaves methanol extract, its fractions and standard.

\begin{tabular}{ll}
\hline Plant Extract Fraction & \% of Hemolysis \\
\hline 100\% Methanol & $1.46 \pm 0.14$ \\
Chloroform & $2.64 \pm 0.11$ \\
Ethylacetate & $1.40 \pm 0.04$ \\
$n$-Butanol & $1.01 \pm 0.04$ \\
$n$-Hexane & $2.09 \pm 0.08$ \\
Phosphate Buffer Saline (PBS) & 0 \\
Triton X-100 & $100 \pm 0.61$ \\
\hline
\end{tabular}

\subsection{Antimicrobial Activity}

The plant exhibited considerable antimicrobial activity against all the strains tested as reported in Table 4. The results from the disc diffusion method, followed by measurement of minimum inhibitory concentration (MIC), indicated that the methanol extract showed strong inhibitory activity against A. flavus and A. alternata, with the highest inhibition zones (27.5 and $20.75 \mathrm{~mm}$ ) and the lowest MIC values (18.4 and $69.4 \mathrm{mg} / \mathrm{mL}$ ). Methanol extract showed no activity against $P$. multocida and $A$. niger. Chloroform fraction showed strong inhibitory action against $R$. solani and A. flavus with high inhibition zones (26.7 and $19 \mathrm{~mm}$ ) and reduced MIC values $(20.4$ and $25.1 \mathrm{mg} / \mathrm{mL})$. A weak activity was exhibited against $P$. multocida, and $S$. aureus. Ethylacetate fraction showed good inhibitory activity only against $E$. coli, with an inhibition zone of $18.75 \mathrm{~mm}$ and the lowest MIC value $(94.2 \mathrm{mg} / \mathrm{mL})$. Ethylacetate fraction was inactive to inhibit the growth of A. flavus, A. alternata and $R$. solani. $n$-Butanol fraction showed a strong activity against $E$. coli with highest inhibition zone $(26.8 \mathrm{~mm})$ and the lowest MIC value $(15.2 \mathrm{mg} / \mathrm{mL})$ if compared to the standard drug rifampicin whose inhibition zone was of $21.5 \mathrm{~mm}$ (MIC $62.1 \mathrm{mg} / \mathrm{mL}$ ). Little activity was exhibited against $B$. subtilis, with the small inhibition zone $(13 \mathrm{~mm})$ and the highest MIC value (170 mg/mL). $n$-hexane fraction showed strong inhibitory action against $P$. multocida, with the inhibition zone $(25.75 \mathrm{~mm})$ and the lowest MIC value $(27.4 \mathrm{mg} / \mathrm{mL})$; this fraction resulted inactive against $B$. subtilis.

Table 4. Antimicrobial activity of a methanol extract and fractions of A. attenuata leaves.

\begin{tabular}{|c|c|c|c|c|c|c|c|}
\hline \multirow{2}{*}{$\begin{array}{l}\text { Tested } \\
\text { Microorganism }\end{array}$} & \multicolumn{5}{|c|}{ Methanol Extract and Its Fractions (Diameter of Inhibition Zone, mm) } & \multicolumn{2}{|c|}{ Standard Drugs } \\
\hline & Methanol & Chloroform & Ethylacetate & $n$-Butanol & $n$-Hexane & Rifampcin & Fluconazole \\
\hline B. subtilis & $14.0 \pm 1.41^{b}$ & $11.5 \pm 1.11^{\mathrm{c}, \mathrm{d}}$ & $10.0 \pm 1.58^{\mathrm{d}}$ & $13.0 \pm 0.70^{\mathrm{b}, \mathrm{c}}$ & 0 & $30.0 \pm 1.41^{\mathrm{a}}$ & n.d \\
\hline P. multocida & 0 & $10.0 \pm 0.70^{\mathrm{d}}$ & $12.5 \pm 1.118^{\mathrm{d}}$ & $16.5 \pm 1.65^{c}$ & $25.75 \pm 2.58^{b}$ & $29.75 \pm 0.43^{a}$ & n.d \\
\hline S. aureus & $9.75 \pm 0.43^{c}$ & $10.0 \pm 0.70^{c}$ & $10.75 \pm 0.78^{c}$ & $19.25 \pm 0.43^{b}$ & $10.5 \pm 0.5^{c}$ & $31.75 \pm 2.04^{\mathrm{a}}$ & n.d \\
\hline E. coli & $17.0 \pm 1.22^{\mathrm{b}, \mathrm{c}}$ & $14.2 \pm 0.82^{\mathrm{c}}$ & $18.75 \pm 0.43^{\mathrm{a}}$ & $26.8 \pm 0.62^{\mathrm{b}}$ & $14.25 \pm 2.27^{\mathrm{c}}$ & $21.5 \pm 2.06^{\mathrm{a}}$ & n.d \\
\hline A. niger & 0 & $10.2 \pm 1.47^{\mathrm{b}}$ & $10.5 \pm 1.11^{\mathrm{b}}$ & $16.3 \pm 1.65^{\mathrm{a}}$ & $16.5 \pm 1.68^{b}$ & n.d & $18.5 \pm 1.11^{\mathrm{a}}$ \\
\hline A. flavus & $27.5 \pm 2.5^{b}$ & $19 \pm 0.707^{c}$ & 0 & $19.2 \pm 0.82^{c}$ & $17.0 \pm 1.00^{\mathrm{c}}$ & n.d & $1.0 \pm 1.00^{\mathrm{a}}$ \\
\hline
\end{tabular}


Table 4. Cont.

\begin{tabular}{|c|c|c|c|c|c|c|c|}
\hline \multirow{2}{*}{$\begin{array}{l}\text { Tested } \\
\text { Microorganism }\end{array}$} & \multicolumn{5}{|c|}{ Methanol Extract and Its Fractions (Diameter of Inhibition Zone, mm) } & \multicolumn{2}{|c|}{ Standard Drugs } \\
\hline & Methanol & Chloroform & Ethylacetate & n-Butanol & n-Hexane & Rifampcin & Fluconazole \\
\hline A. alternata & $20.75 \pm 0.43^{b}$ & $14.5 \pm 1.5^{c}$ & 0 & $19.5 \pm 0.43^{b}$ & $12.25 \pm 0.5^{\mathrm{d}}$ & n.d & $25.5 \pm 1.18^{\mathrm{a}}$ \\
\hline R. solani & $16.50 \pm 1.65^{\mathrm{d}}$ & $26.7 \pm 2.38^{b}$ & 0 & $20.0 \pm 0.707^{\mathrm{c}}$ & $14.75 \pm 2.94^{\mathrm{d}}$ & n.d & $30.25 \pm 0.43^{\mathrm{a}}$ \\
\hline \multicolumn{8}{|c|}{ Minimum Inhibitory Concentration (MIC) mg/mL. } \\
\hline B. subtilis & $158 \pm 1.15$ & $205 \pm 2.71$ & $250 \pm 2.10$ & $170 \pm 1.15$ & 0 & $8.45 \pm 0.25$ & n.d \\
\hline P. multocida & 0 & $250 \pm 2.47$ & $185 \pm 1.25$ & $115 \pm 1.28$ & $27.4 \pm 0.64$ & $9.5 \pm 0.45$ & n.d \\
\hline S. aureus & $252 \pm 1.45$ & $250 \pm 2.35$ & $220 \pm 2.40$ & $89.3 \pm 0.84$ & $240 \pm 2.45$ & $5.32 \pm 0.15$ & n.d \\
\hline E. coli & $110 \pm 0.75$ & $152 \pm 0.79$ & $94.2 \pm 0.87$ & $15.2 \pm 1.15$ & $140 \pm 1.45$ & $62.1 \pm 0.45$ & n.d \\
\hline A. niger & 0 & $244 \pm 2.24$ & $240 \pm 2.85$ & $118 \pm 1.12$ & $115 \pm 1.15$ & n.d & $98.2 \pm 0.55$ \\
\hline A. flavus & $18.4 \pm 0.75$ & $25.1 \pm 0.55$ & 0 & $89.5 \pm 0.52$ & $110 \pm 1.52$ & n.d & $6.4 \pm 0.25$ \\
\hline A. alternata & $69.4 \pm 0.25$ & $142 \pm 0.25^{\mathrm{c}}$ & 0 & $85.4 \pm 0.75$ & $189 \pm 0.95$ & n.d & $27.4 \pm 0.15$ \\
\hline R. solani & $115 \pm 0.75$ & $20.4 \pm 0.75$ & 0 & $80.2 \pm 0.85$ & $140 \pm 0.75$ & n.d & $7.8 \pm 0.16$ \\
\hline
\end{tabular}

Data are expressed as the mean \pm standard deviation; values having different letters differ significantly $(p<0.05)($ n.d. $=$ not detected).

Sanchez et al. [8] reported antifungal activity of A. asperrima and A. striata flowers extracts against A. flavus for both agave methanol extracts with a better antifungal effect. These results are in agreement with our analysis where methanol extract exhibited a strong inhibitory action against A. flavus and good inhibitory effects against all tested fungal strains. A. flavus causes many diseases both in humans and animals as aspergillosis of the lungs and sometimes causing corneal, otomycotic, and nasoorbital infections.

\section{Experimental}

\subsection{Plant Material}

The leaves of the plant A. attenuata were collected on April 2010 from the Botanical Garden, University of Agriculture, Faisalabad, Pakistan. The plant specimens were further identified by Mansoor Hameed, Department of Botany University of Agriculture Faisalabad, Pakistan where a voucher specimen has been deposited.

\subsection{Preparation of Extract and Organic Fractions}

Four kilograms of fresh leaves were washed with distilled water to remove dust and other extraneous matter. The shade dried leaves were powdered $(80 \mathrm{mesh})$. Five hundred grams of powdered leaves were extracted at room temperature for 5 days with $3 \mathrm{~L}$ of methanol. The extract was filtered through Whatman No. 1 filter paper and then concentrated at $45^{\circ} \mathrm{C}$, using a rotary vacuum evaporator. The methanol extract was then stored at $-4{ }^{\circ} \mathrm{C}$. The residue $(85 \mathrm{~g})$ was dissolved in distilled water and extracted successively with $n$-hexane (30 g residue), chloroform (15 g) ethylacetate (20 g), and $n$-butanol (15 g).

\subsection{Gas Chromatography/Mass Spectrometry Analysis}

The GC-MS analysis of the $n$-hexane fraction was performed using GC 6850 Network gas chromatographic system equipped with 7683 B series auto injector and 5973 inert mass selective 
detector (Agilent Technologies USA). Compounds were separated on an HP-5 MS capillary column having $5 \%$ phenyl polysiloxane as stationary phase, column length $30.0 \mathrm{~m}$, internal diameter $0.25 \mathrm{~mm}$ and film thickness $0.25 \mu \mathrm{m}$. The temperature of injector was $300{ }^{\circ} \mathrm{C}$ and $1.0 \mu \mathrm{L}$ of sample was injected in the split mode with split ratio 30:1. Helium was used as carrier gas, with a flow rate of $1.5 \mathrm{~mL} / \mathrm{min}$. The temperature program was: initial temperature $150{ }^{\circ} \mathrm{C}$ and held for $1 \mathrm{~min}$, then ramping at rate of $10{ }^{\circ} \mathrm{C} / \mathrm{min}$ up to $290{ }^{\circ} \mathrm{C}$ and finally hold at this temperature for $5 \mathrm{~min}$. The temperature of MSD transfer line was $300{ }^{\circ} \mathrm{C}$. For mass spectra determination MSD was operated in electron ionization (EI) mode, with the ionization energy of $70 \mathrm{eV}$, while the mass range scanned was 3-500 $\mathrm{m} / \mathrm{z}$. The temperature of ion source was $230{ }^{\circ} \mathrm{C}$ and that of MS quadropole $150{ }^{\circ} \mathrm{C}$. The identification of components was based on comparison of their mass spectra with those of NIST mass spectral library [22-23].

\subsection{Antimicrobial Assay}

\subsubsection{Test Microorganisms}

Aspergillus niger ATCC 10595, Aspergillus flavus ATCC 32612, Alternaria alternata ATCC 20084, Rhizoctonia solani locally isolated, were used as the fungal tested organisms and Pasturella multocida locally isolated, Escherichia coli ATCC 25922, Bacillus subtilis JS 2004, Staphylococcus aureus API Staph tac 6736153 were used as the bacterial tested organisms. The pure bacterial and fungal strains were obtained from the Department of Veterinary Microbiology, University of Agriculture, Faisalabad, Pakistan. The bacterial strains were cultured overnight at $37{ }^{\circ} \mathrm{C}$ in nutrient agar (Oxoid, Hampshire, UK) while fungal strains were cultured overnight at $28{ }^{\circ} \mathrm{C}$ using potato dextrose agar (Oxoid).

\subsubsection{Disc Diffusion Method}

Antimicrobial activity of the methanol extract and of its fractions was determined by using the disc diffusion method [24]. All samples (dry residue) were dissolved in 10\% sterile dimethyl sulfoxide. The discs (6 mm diameter) were impregnated with $20 \mathrm{mg} / \mathrm{mL}$ extract/fractions $(100 \mu \mathrm{L} / \mathrm{disc})$ placed aseptically on the inoculated agar. Discs injected with $100 \mu \mathrm{L}$ of respective solvents served as a negative controls, rifampcin (100 $\mu \mathrm{L} /$ disc) (Oxoid) and fluconazole (100 $\mu \mathrm{L} /$ disc) (Oxoid) were used as positive reference for bacteria and fungi, respectively. The petri dishes were incubated at $37 \pm 0.1{ }^{\circ} \mathrm{C}$ for $20-24 \mathrm{~h}$ and $28 \pm 0.3{ }^{\circ} \mathrm{C}$ for $40-48 \mathrm{~h}$ for bacteria and fungi, respectively. At the end of period, the inhibition zones formed on the media were measured. The positive antimicrobial activity was read based on growth inhibition zone.

\subsubsection{Resazurin Microtitre-Plate Assay}

The minimum inhibitory concentration (MIC) of the plant extract/fractions was evaluated by a modified resazurin microtitre-plate assay reported by Sarker and co-workers [25] with some modifications. Briefly, a volume of $100 \mu \mathrm{L}$ of each extract and fractions solution in $10 \%$ dimethyl sulfoxide (DMSO, $v / v$ ) was transferred into the first row of the 96 well plates. To all other wells, $50 \mu \mathrm{L}$ of nutrient broth and Muller Hinton broth for bacteria and fungi respectively were added. Two-fold serial dilutions were performed using a multichannel pipette such that each well had $50 \mu \mathrm{L}$ 
of the test material in serially descending concentrations. To each well, $10 \mu \mathrm{L}$ of resazurin indicator solution (prepared by dissolving $270 \mathrm{mg}$ resazurin tablet in $40 \mathrm{~mL}$ of sterile distilled water) were added. Finally, $10 \mu \mathrm{L}$ of bacterial/fungal suspension were added to each well. Each plate was wrapped loosely with aluminum foil. Each plate had a set of controls: a column with broad spectrum antibiotics as positive control, a column with all solutions with the exception of the test samples, a column with all solutions with the exception of the bacterial/fungal solution adding $10 \mu \mathrm{L}$ of broths instead and a column with respective solvents as a negative control. The plates were prepared in triplicate, and incubated at $37 \pm 0.1{ }^{\circ} \mathrm{C}$ for $20-24 \mathrm{~h}$ and $28 \pm 0.3{ }^{\circ} \mathrm{C}$ for $40-48 \mathrm{~h}$ for bacteria and fungi, respectively The absorbance was measured at $620 \mathrm{~nm}$ by micro quant for fungus and at $500 \mathrm{~nm}$ for bacteria. The color change was then assessed visually. The growth was indicated by color changes from purple to pink or colorless. The lowest concentration at which color change appeared was taken as the MIC value.

\subsection{In Vitro Hemolytic Activity}

Hemolytic activity of the plant was checked by the reported method of Powell and co-workers [26]. Three milliliter of freshly obtained heparinized human blood was gently mixed, poured into a sterile $15 \mathrm{~mL}$ polystyrene screw-cap tube and centrifuged for $5 \mathrm{~min}$, at $850 \mathrm{~g}$. The supernatant was poured off and the viscous pellet washed three additional times with $5 \mathrm{~mL}$ of chilled $\left(4{ }^{\circ} \mathrm{C}\right)$ sterile isotonic phosphate-buffered saline (PBS) solution, adjusted to $\mathrm{pH}$ 7.4. The washed cells were suspended in a final volume of $20 \mathrm{~mL}$ chilled, sterile PBS and the cells counted on a haemacytometer. The blood cell suspension was maintained on wet ice and diluted with sterile PBS to $7.068 \times 10^{8}$ cells $\mathrm{mL}^{-1}$ for each assay. Aliquots of $20 \mu \mathrm{L}$ of plant extract/fractions were aseptically placed into $2.0 \mathrm{~mL}$ microfuge tubes. For each assay, $0.1 \%$ Triton X-100 was used as the positive, $100 \%$ lytic control and PBS as the negative, $0 \%$ lytic control. Aliquots of $180 \mu \mathrm{L}$ diluted blood cell suspension were aseptically placed into each $2-\mathrm{mL}$ tube and gently mixed three times with a wide mouth pipette tip. Tubes were incubated for $35 \mathrm{~min}$ at $37{ }^{\circ} \mathrm{C}$ with agitation (80 revolutions per minute). Immediately following incubation, the tubes were placed on ice for $5 \mathrm{~min}$, then centrifuged for $5 \mathrm{~min}$ at $1310 \mathrm{~g}$. Aliquots of $100 \mu \mathrm{L}$ of supernatant were carefully collected, placed into a sterile $1.5 \mathrm{~mL}$ microfuge tube, and diluted with 900 $\mu \mathrm{L}$ chilled, sterile PBS. All tubes were maintained on wet ice after dilution. Then $200 \mu \mathrm{L}$ were placed into 96 well plates, and three replicates was taken in well plate which contain one positive and one negative. Absorbance at $576 \mathrm{~nm}$ was then measured on a microquant. The experiment was done in triplicate. Percent hemolysis was calculated by following formula:

$\%$ hemolysis $=$ Abs $($ sample absorbance $) /$ Abs $($ control absorbance $) \times 100$

\subsection{Evaluation of Antioxidant Activity}

\subsubsection{Determination of Total Phenolic Contents (TPC)}

Amount of TPC were assessed using Folin-Ciocalteu reagent procedure [27]. Briefly, $50 \mathrm{mg}$ of dry mass of crude extract/fraction was mixed with $0.5 \mathrm{~mL}$ of Folin-Ciocalteu reagent and $7.5 \mathrm{~mL}$ deionized water. The mixture was kept at room temperature for $10 \mathrm{~min}$, and then $1.5 \mathrm{~mL}$ of $20 \%$ sodium carbonate $(w / v)$ was added. The mixture was heated in a water bath at $40{ }^{\circ} \mathrm{C}$ for 20 min and then cooled in an ice bath; finally absorbance at $755 \mathrm{~nm}$ was measured (Hitachi U-2001 spectrophotometer). 
Amounts of TP were calculated using a calibration curve for gallic acid $(10-100 \mathrm{ppm})\left(R^{2}=0.9986\right)$. The results were expressed as gallic acid equivalents (GAE) of dry plant matter.

\subsubsection{Determination of Total Flavonoid Contents (TFC)}

The Total Flavonoid Content (TFC) in plant extract and fractions was determined following the procedure as described by Dewanto and co-workers [28]. Plant extract/fractions of each material (1 mL containing $0.1 \mathrm{~g} / \mathrm{mL}$ ) was placed in a $10 \mathrm{~mL}$ volumetric flask, then added distilled water $5 \mathrm{~mL}$ and $0.3 \mathrm{~mL}$ of $5 \% \mathrm{NaNO}_{2}$ was added to each volumetric flask initially; after 5 min., $0.6 \mathrm{~mL}$ of $10 \% \mathrm{AlCl}_{3}$ was added. After another $5 \mathrm{~min}, 2 \mathrm{~mL}$ of $1 \mathrm{M} \mathrm{NaOH}$ was added and volume made up with distilled water. Then solution was mixed. At $510 \mathrm{~nm}$ absorbance of the reaction mixture was taken using a spectrophotometer. TFC were evaluated as catechin equivalents ( $\mathrm{g} / 100 \mathrm{~g}$ of dry plant matter).

\subsubsection{DPPH Radical Scavenging Assay}

The 2,2-diphenyl-1-picrylhydrazyl radical (DPPH) assay was carried out spectrophotometrically as described by Bozin and co-workers [29]. The antioxidant activity of the methanol extract and various fractions $(0.1 \mathrm{mg} / \mathrm{mL})$ were mixed with $1 \mathrm{~mL}$ of $90 \mu \mathrm{M}$ DPPH solution and made up with $95 \%$ methanol, to a final volume of $4 \mathrm{~mL}$. After $1 \mathrm{~h}$ incubation period at room temperature, the absorbance was recorded at $515 \mathrm{~nm}$. Inhibition of free radical by DPPH in percent (\%) was calculated in the following way:

$$
\text { Inhibition }(\%)=100 \times\left(\mathrm{Abs}_{\text {blank }}-\mathrm{Abs}_{\text {sample }} / \mathrm{Abs}_{\text {blank }}\right)
$$

where $\mathrm{Abs}_{\text {blank }}$ is the absorbance of the control (containing all reagents except the test samples), and $\mathrm{Abs}_{\text {sample }}$ is the absorbance of the test samples.

\subsubsection{Antioxidant Activity in Linoleic Acid System}

The antioxidant activity of A. attenuata leaves methanol extract and its fractions was also determined in terms of measurement of percent inhibition of peroxidation in linoleic acid system following a method reported by Iqbal and Bhanger [30]. Extract/fractions (5 mg) were added to a solution mixture of linoleic acid $(0.13 \mathrm{~mL}), 99.8 \%$ ethanol $(10 \mathrm{~mL})$ and $10 \mathrm{~mL}$ of $0.2 \mathrm{M}$ sodium phosphate buffer (PH 7.0). Total mixture was diluted to $25 \mathrm{~mL}$ with distilled water. The solution was incubated at $40{ }^{\circ} \mathrm{C}$ and the degree of oxidation was measured following thiocyanate method [28] with $10 \mathrm{~mL}$ of ethanol (75\%), $0.2 \mathrm{~mL}$ of an aqueous solution of ammonium thiocyanate $(30 \%), 0.2 \mathrm{~mL}$ of sample solution and $0.2 \mathrm{~mL}$ of ferrous chloride $\left(\mathrm{FeCl}_{2}\right)$ solution $(20 \mathrm{mM}$ in $3.5 \% \mathrm{HCl})$ being added sequentially. After $3 \mathrm{~min}$ of stirring, the absorption values of mixtures measured at $500 \mathrm{~nm}$ were taken as peroxide contents. A control was performed with linoleic acid but without extracts. Synthetic antioxidants butylated hydroxytoluene (BHT) and ascorbic acid (200 ppm) were used as positive control. The maximum peroxidation level observed at $360 \mathrm{~h}$ (15 days) in the sample that contained no antioxidant component was used as a test point. The percent inhibition of linoleic acid peroxidation was calculated as follows:

Percent inhibition of linoleic acid peroxidation $=100-\frac{\text { Abs. increase of sample at } 360 \mathrm{~h}}{\text { Abs. increase of control at } 360 \mathrm{~h}} \times 100$ 


\subsubsection{Determination of Reducing Power}

The reducing power of the extract/fractions was determined according to the procedure described by Yen and co-workers [31] with little modification. Equivalent volume of leaves crude extracts/fractions containing $1.0 \mathrm{mg}$ of dry matter was mixed with sodium phosphate buffer $(5.0 \mathrm{~mL}$, $0.2 \mathrm{M}, \mathrm{pH}$ 6.6) and potassium ferricyanide $(5.0 \mathrm{~mL}, 1.0 \%)$; the mixture was incubated at $50{ }^{\circ} \mathrm{C}$ for $20 \mathrm{~min}$. Then $5 \mathrm{~mL}$ of $10 \%$ trichloroacetic acid was added and centrifuged at $980 \mathrm{~g}$ for $10 \mathrm{~min}$ at $5{ }^{\circ} \mathrm{C}$ in a refrigerated centrifuge (Centrifuge H-200NR, Kokusan, Japan). The upper layer of the solution $(5.0 \mathrm{~mL})$ was diluted with $5.0 \mathrm{~mL}$ of distilled water and ferric chloride $(1.0 \mathrm{~mL}, 0.1 \%)$ and absorbance noted at $700 \mathrm{~nm}$ (Hitachi U-2001 Spectrophotometer).

\subsection{Statistical Analysis}

Each sample was analyzed individually in triplicate for its data were reported as mean $(n=3 \times 3 \times 1) \pm$ standard deviation $(n=3 \times 3 \times 1)$. Data were analyzed by analysis of variance (ANOVA) using Minitab 2000 Version 13.2 statistical software (Minitab Inc., Pennysalvania, USA).

\section{Conclusions}

Data obtained in the present study confirmed the considerable biological activities possessed by A. attenuata. The presence of biologically important phytochemicals in the plant extracts may contribute to their medicinal value and potential sources for useful drugs. The investigated plant may be processed for pharmaceutical and natural therapies for the treatment of ailments in humans. Further the antioxidant properties exhibited by this plant indicate its possible use as a functional ingredient for processing into health foods in the food industry.

\section{References}

1. Policegoudra, R.S.; Rehna, K.; Rao, L.J.; Aradhya, S.M. Antimicrobial, antioxidant, cytotoxicity and platelet aggregation inhibitory activity of a novel molecule isolated and characterized from mango ginger (Curcuma amada Roxb.) rhizome. J. Biosci. 2010, 35, 231-240.

2. Vichi, S.; Eseer, Z.; Jugl, K.; Franz, M.C. Determination of the presence of antioxidants derived from sage and organic extracts added to the animal fat by means of assessment of the radical scavenging capacity by photochemilumenescence analysis. Nahrung 2001, 45, 101-104.

3. Gupta, A.K. Quality standards of Indian Medicinal plants. Indian Council Med. Res. 2003, 2, 62-65.

4. Bedour, M.S.; Elgamal, M.H.A.; El-Tawil, B.A.H. Steroid sapogenins. Part XV. The constituents of Agave utahensis var. nevadensis, A. lophanta and A. parasana. Planta Med. 1979, 36, 180-181.

5. Tyler, V.E.; Brady, L.R.; Robbers, J.E. Pharmacognosy; Lea \& Febriger: Philadelphia, PA, USA, 1988.

6. Peana, A.; Moretti, M.D.L.; Manconi, V.; Desole, G.; Pippia, P. Antiinflammatory activity of aqueous extracts and steroidal sapogenins of Agave americana. Planta Med. 1997, 63, 199-202.

7. Bianchi, E.; Cole, J.R. Antitumour agents from Agave schotti (Amaryllidaceae). J. Pharm. Sci. 1969, 58, 589-591. 
8. Sanchez, E.; Heredia, N.; Garcia, S. Inhibition of growth and mycotoxin production of Aspergillus flavus and Aspergillus parasiticus by extracts of Agave species. Int. J. Food Microbiol. 2005, 98, 271-279.

9. Verastegui, A.; Verde, J.; Garcia, S.; Heredia, N.; Oranday, A.; Rivas, C. Species of Agave with antimicrobial activity against selected pathogenic bacteria and fungi. World J. Microbiol. Biotechnol. 2008, 24, 1249-1252.

10. Davidson, J.R.; Montellano, B.R. The antibacterial properties of an Aztec wound remedy. J. Ethnopharmacol. 1983, 8, 149-161.

11. Garcia-Mendoza, A. Riqueza y Endemismos de la Familia Agavaceae en Mexico; In Conservación de Plantas en Peligro de Extinción: Diferentes Enfoques; Linares, E., Davila, P., Chiang, F., Bye, R., Elias, T., Eds.; Universidad Nacional Autónoma de México: Mexico City, México, 1995; p. 51.

12. Hocking, G.M. A Dictionary of Natural Products; Plexus Publishing Inc.: Medford, NJ, USA, 1997; Volume 7.

13. Mendes, T.P.; De Medeiros, S.G.; Da Silva Pereira, G.; Parente, J.P. A new steroidal sapogenin from Agave attenuate. Nat. Prod. Res. 2004, 18, 183-188.

14. Da Silva, B.P.; de Sousa, A.C.; Silva, G.M.; Mendes, T.P.; Parente, J.P. A new steroidal bioactive saponin from Agave attenuata. Z. Natorforsch. C. 2002, 57, 423-428.

15. Bedour, M.S.; Fayez, M.B.E. Steroidal sapogenins. V. The constituents of Agave attenuata, A. macracantha and A. angustifolia. J. Chem. UAR 1961, 4, 265-272.

16. Brackenbury, T.D.; Appleton, C.C. A comprehensive evaluation of Agave attenuata, a candidate plant molluscicide in South Africa. Acta Trop. 1997, 68, 201-213.

17. Brackenbury, T.D. Gross histopathological effects of and extract of Agave attenuate on the epithelium of the digestive tract of Bulinus africanus. Ann. Trop. Med. Parasitol. 1999, 93, 519-526.

18. Gutierrez, A.; Rodriguez, I.M.; Rio, J.C. Chemical composition of lipophilic extractives from sisal (Agave sisalana) fibers. Ind. Crop. Prod. 2008, 28, 81-87.

19. Anwar, F.; Ali, M.; Hussain A.I. Shahid, M. Antioxidant and antimicrobial activities of essential oil and extracts of fennel (Foeniculum vulgare Mill.) seeds from Pakistan. Flavour Frag. J. 2009, 24, 170-176.

20. Bushra, S.; Anwar, F.; Przybylski, R. Antioxidant activity of phenolic components present in barks of Azadirachta indica, Terminalia arjuna, Acacia nilotica and Eugenia jambolana Lam. Trees. Food Chem. 2007, 104, 1106-1114.

21. Grishkovets, V.I.; Tsvetkov, O.Y.; Shashkov, A.S.; Chirva, V.Y. Triterpene glycosides of

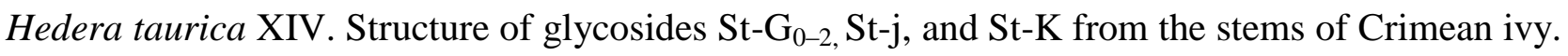
Chem. Nat. Compd. 1997, 33, 305-309.

22. Massada, Y. Analysis of Essential Oils by Gas Chromatography and Mass Spectrometry; John Wiley and Sons: New York, NY, USA, 1976.

23. Mass Spectral Library. Available online: http://www.sisweb.com/software/ms/nist.htm (accessed on 23 May 2002).

24. National Committee for Clinical Laboratory Standards. Performance Standards for Antimicrobial Disc Susceptibility Test, 5th ed; Approved Standard, M2-A6; Clinical and Laboratory Standards Institute: Wayne, PA, USA, 1997. 
25. Sarker, S.D.; Nahar, L.; Kumarasamy, Y. Microtitre plate-based antibacterial assay incorporating resazurin as an indicator of cell growth, and its application in the in vitro antibacterial screening of phytochemicals. Methods 2007, 42, 321-324.

26. Powell, W.A.; Catranis, C.M.; Maynard, C.A. Design of self-processing antimicrobial peptides for plant protection. Lett. Appl. Microbiol. 2000, 31, 163-168.

27. Chaovanalikit, A.; Wrolstad, R.E. Total anthocyanins and total phenolics of fresh and processed cherries and their antioxidant properties. Food Chem. Toxicol. 2004, 69, 67-72.

28. Dewanto, V.; Wu, X.; Adom, K.K.; Liu, R.H. Thermal processing enhances the nutritional value of tomatoes by increasing total antioxidant activity. J. Agric. Food Chem. 2002, 50, 3010-3014.

29. Bozin, B.; Mimica-Dukie, N.; Simin, N.; Anackov, G. Characterization of the volatile composition of essential oil of some lamiaceae species and the antimicrobial and antioxidant activities of the entire oils. J. Agric. Food Chem. 2006, 54, 1822-1828.

30. Iqbal, S.; Bhanger, M.I. Antioxidant properties and components of some commercially available varieties of rice bran in Pakistan. Food Chem. 2005, 93, 265-272.

31. Yen, G.C.; Duh, P.D.; Chuang, D.Y. Antioxidant activity of anthraquinones and anthrone. Food Chem. 2000, 70, 307-315.

(C) 2012 by the authors; licensee MDPI, Basel, Switzerland. This article is an open access article distributed under the terms and conditions of the Creative Commons Attribution license (http://creativecommons.org/licenses/by/3.0/). 